Proceedings of the 2009 Winter Simulation Conference

M. D. Rossetti, R. R. Hill, B. Johansson, A. Dunkin and R. G. Ingalls, eds.

\title{
S.U.C.C.E.S.S.F.U.L.: A FRAMEWORK FOR DESIGNING DISCRETE EVENT SIMULATION COURSES
}

\author{
Heriberto Garcia \\ Dept. of Industrial and Systems Engineering \\ Tecnologico de Monterrey \\ Monterrey, Nuevo León 64849, México
}

\author{
Martha A. Centeno \\ Dept. of Industrial and Systems Engineering \\ Florida International University \\ Miami, FL, 33174, USA
}

\begin{abstract}
Teaching a discrete event simulation (DES) course to undergraduates represents a challenge for instructors, particularly for the novice ones. There are many issues to address in designing the course, among which are the scope of the course, focus area of the course, technical depth of the course, and the role of a simulation packages in the course. How to introduce simulation has been a fundamental educational issue for a while. New teaching paradigms and the explosion tools available offers opportunities to design a course that is holistic. This paper presents a framework that enables a holistic design of a DES course such that students acquire a strong knowledge base regarding the use of DES in the real world. This paper also includes an example of how to use this framework.
\end{abstract}

\section{INTRODUCTION}

Teaching discrete event simulation (DES) at the undergraduate level is a challenge for instructors. A first course in DES modeling is typically given at the junior or senior year, and it typically has a first course in statistics as pre-requisite. On occasions, it also has a systems dynamics course as pre-requisite (ITESM, 2009). In many institutions, students take the statistics course from the Department of Statistics, which offers it as a service course to the entire university community; hence, the class sizes tend to be large (50+), and the emphasis tends to be broad rather than deep. The DES method requires strong foundations in the areas of statistical analysis, stochastic modeling, and systems analysis. To make matters worse, in some universities the introductory course is taking by a mix pool of undergraduate and first year graduates. These realities pose challenges for instructors because the pool of students lacks these foundations. Instructors have to impart such knowledge anew or enable the remembering of it. Furthermore, in some countries, the syllabus of the course is prescribed, with some flexibility as to the order of concept delivery. DES instructors must identify the concepts to teach, teaching order, and teach methods. How to introduce simulation has been a fundamental educational issue for a while (Standridge et al., 2005). The underlying requirements for the teaching protocol is that it must enable students acquire a deep knowledge and understanding of how to use simulation in their professional lives. This has to be done making sure students are not overwhelmed, but rather they become interested in the subject. These challenges are not trivial. Failure to properly transferring simulation concepts may result in the technique not being used properly, creating professionals who are skeptical to the application of simulation in real problems. Inadequate exposure to simulation may result in a professional who develops unrealistic expectations about what is possible to attain with simulation, to the point that they may attribute to it some magical capabilities to predict the future (Centeno and Carrillo 2001).

The objectives of a DES course may vary from curriculum to curriculum. Instructor design their lectures according to the course objectives, experience in the simulation field, and personal teaching background and preferences. However, simulation courses always seek to provide students with an applied understanding of the role of modeling and simulation in the analysis of typical engineering Systems (Standridge et al. 2005). There are elements of a DES course that should be common regardless of who and where the course is taught. These common elements include modeling, statistical tools, data analysis, and what-if analysis. The challenge resides in how to deliver, how much depth to deliver, and how to organize these common elements, so that when the unique elements are added, we have a holistic, cohesive, and well-organized course. It is necessary for the course to have an organization that builds upon students' prior skills in regards to problem solving. This organizational requirement opens an opportunity to define a framework to help DES instructors in designing a robust simulation course for undergraduates. 


\section{Garcia and Centeno}

In general, a framework provides a better understanding of a system's complexity, such that the partitioning and simplification of the system's elements can be studied through a common modeling language and methodology (Kosanke and Zelm, 1999). Simulation frameworks are not new. In the literature, there are some examples of frameworks related to simulation applications such as modeling supply chains (Van der Zee and Van der Vorst 2005), evaluate simulation software (Nikoukaran et al. 1999), or frameworks for discrete event model simulation (Wolfgang and Østerbye 1998). The majority of these frameworks have been focused on the use of simulation. We proposed a framework that is focused on the teaching of DES, and not on the algorithms or application of DES. In this context, a conceptual design framework is a structure that 1) enables a better understanding of the challenges of teaching DES to undergraduates, 2) it outlines possible course of actions for different stages in the course, and 3) presents preferred and reliable approaches to knowledge delivery.

In the following sections, we describe a DES teaching framework called S.U.C.C.E.S.S.F.U.L., its requirements, an example of using it, and some suggestions for future work related to this framework.

\section{FRAMEWORK REQUIREMENTS}

A framework may be defined in several ways. In the literature, there are frameworks defined through:

- a matrix such as the Zachman framework for enterprise architectures (Zachman 1999),

- a hierarchical diagram such as the framework for evaluating simulation software (Nikoukaran et al. 1999), or

- a philosophical base, which is labeled with an acronym such as PIECES (Performance, Information, Economics, Control, Efficiency, and Service (Whitten et al. 2004)), and CATWOE (Customers, Actors, Transformation, World view, Owner, and Environment (Lehaney and Paul 1996).

Years of experiences have shown us that the more complex to use the framework is, the less it will be used. The DES teaching framework must be structurally simple, while at the same time capture a holistic view of a DES course. A robust framework is one that enables its users to achieve the goal for which the framework was designed in an easy and timely fashion; thus, a DES teaching framework must possess the following characteristics:

1) Be easy to use,

2) Have a checklist of key elements that must be in the DES course,

3) Incorporate didactic strategies, and

4) Be easy to remember the elements of the framework.

\subsection{Ease of Use}

Utilization of a 3-D matrix framework is very appealing for the case of designing DES curses. It would enable the definition of course contents elements (X), incorporation of didactic methods for each element (Y), and incorporation of tools that can be used for each method in each element $(Z)$. However, instructors are familiar with the two dimensional format of syllabus, so instead of asking them to change their thinking paradigm when designing the course, we build upon it. The 2-D matrix approach provides a simple yet sufficient structure for a DES teaching framework.

This structure allows for the integration of events, the sequencing of these events, as well as feedback among the actors. In a 2-D structure, it is relatively easy to reflect a cohesive connection among modeling phases (Design, Build, and Experiment (DBE)), teaching methods, and teaching and learning tools. It is noteworthy to point out that a DES course must be a dynamic course to be effective. The framework, thus, must include didactic strategies that engage active learning, such as Problem Based Learning (PBL), Project Oriented Learning (POL), or Case Based Learning (CBL). Integrating these strategies or, better yet a mixture of them, encourage student-direct learning and problem-solving skills. Thus, students find themselves thrown into a creative environment in which they are active learners (Maxwell et al. 2004). Thus, the designing framework should guide instructors in deciding tools to engage students in collaborative and self-learning activities.

\subsection{Have a Checklist of Key DES Elements}

In regards to the scope of a DES course, time is the major constraints that instructors have to work with. There are so many concepts that one could address in certain concept areas that it is not possible to address them all. For example, one may be exited about teaching what is behind the scenes in the execution of a simulation model that one may be tempted to spend significant amount of time in explaining how random numbers are generated, how they are converted to random numbers, how the event list is updated and how it is maintaining in sorted by time. Another aspect that one may get excited about is in teaching the many techniques that are available to conduct analysis of the simulation output; for instance, one may want to teach Design of Experiments, Regression Analysis, Variance Reduction Techniques, and so forth. However, there is no time for teaching of all of these concepts in addition to the DES concepts (De Vin and Jägstam 2001). Instructor must have guid- 


\section{Garcia and Centeno}

ance in selecting what concepts are necessary in an introductory DES course. The ultimate goal our framework is not to include all concepts, but to include critical one for each element of using the DES methodology. The framework should allow time customized the course by adding depth in some of these elements, as defined by the institution or instructor who teaches offers the course.

The DES project cycle is shown is Figure 1. A DES project cycle is typical of an engineering project. Activities in it belong to one of three broad modeling phases: Designing the model, Building the model, and Experimenting with the model (DBE). To be successful, students need to learn concepts that belong to one of four concept areas: systems modeling, simulation modeling, statistical analysis, and communication skills. Therefore, the elements of the framework must capture the essence of this cycle. The number of elements of the framework should be minimized, ensuring that concepts are delivered cohesively and as complementary packets. We identified ten elements as the minimum necessary to have complete checklist as shown in Table 1.

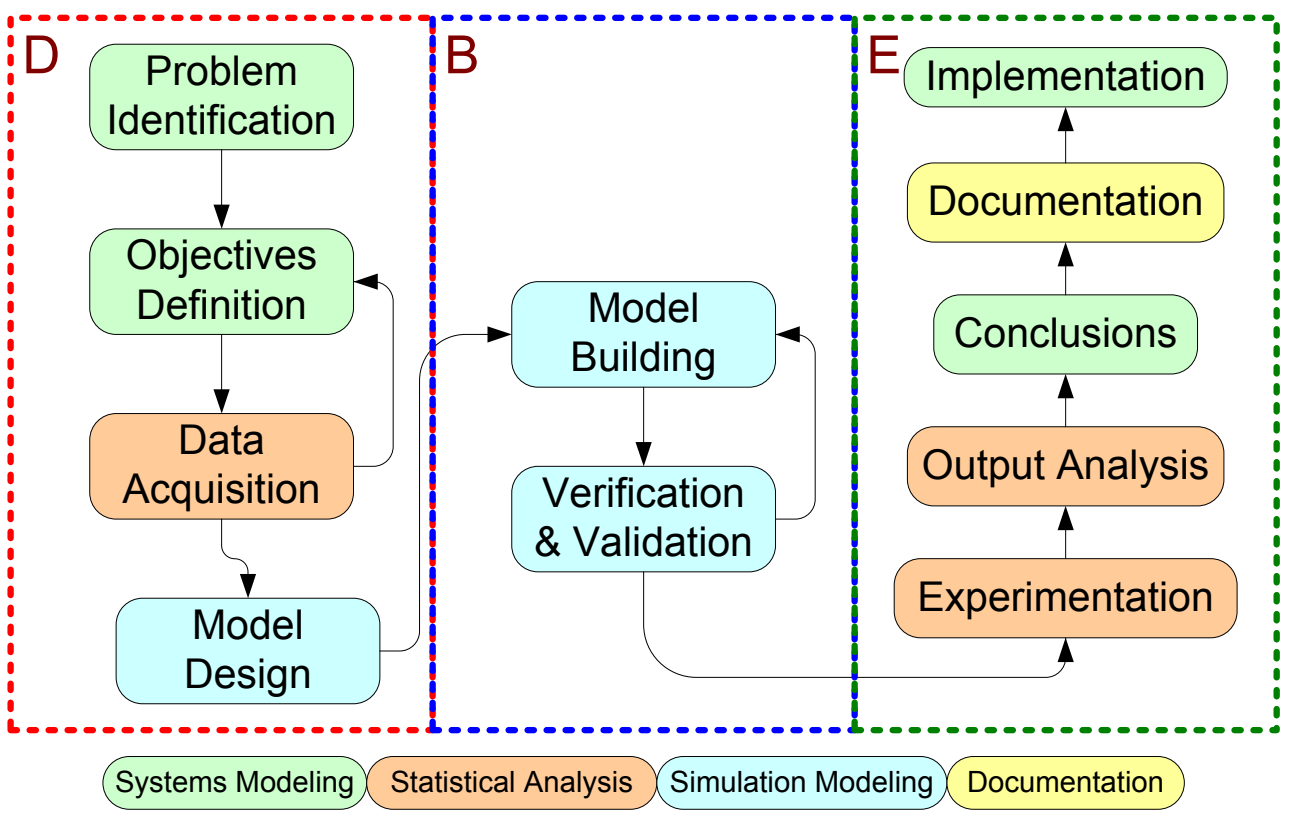

Figure 1: DES Project Cycle

Table 1: DES Concepts - Framework Elements Relationships.

\begin{tabular}{|c|c|c|c|c|}
\hline \# & $\begin{array}{c}\text { Element } \\
\text { Label }\end{array}$ & Meaning & $\begin{array}{c}\text { Concepts } \\
\text { Area }\end{array}$ & $\begin{array}{c}\text { DES Modeling } \\
\text { Phase }\end{array}$ \\
\hline 1 & $\mathbf{S}$ & Standardize Systems Concepts knowledge & Sys & \multirow{3}{*}{ Design the Model } \\
\hline 2 & $\mathbf{U}$ & Unify simulation concepts & Sim & \\
\hline 3 & $\mathbf{C}$ & Convey relationships among system elements & Sys & \\
\hline 4 & $\mathbf{C}$ & Complement concepts for data collection and analysis & Sta & \multirow{4}{*}{ Build the Model } \\
\hline 5 & $\mathbf{E}$ & Establish the importance of modeling accuracy & Sim & \\
\hline 6 & $\mathbf{S}$ & Show simulation modeling strategies & Sim & \\
\hline 7 & $\mathbf{S}$ & Select the appropriate software & Sim & \\
\hline 8 & $\mathbf{F}$ & Formulate post-processing analysis scenarios & Sta & \multirow{3}{*}{$\begin{array}{c}\text { Experiment with } \\
\text { Model }\end{array}$} \\
\hline 9 & $\mathbf{U}$ & Undertake model documentation activities & Com & \\
\hline 10 & $\mathbf{L}$ & Lead student through an integral case study & $\begin{array}{c}\text { Com, Sim, } \\
\text { Sta, Sys }\end{array}$ & \\
\hline
\end{tabular}

\subsection{Incorporate Didactic Strategies}

A DES course is enhanced by the inclusion of one o several didactic strategies such as Case Method, Problem Based Learning (PBL), or Project Oriented Learning (POL). These strategies provide great learning advantages to the students and teaching methods to the novel instructor. For instance, Case Method involves the students intellectually and emotionally, bringing 


\section{Garcia and Centeno}

real situations to the instructional settings. As a result, students can link theory to practice, deal with complexity of a particular situation, or improve judgment, expertise, and enliven teaching (Jennings, 2002).

\subsection{Easy to Remember}

Findings from educational research have shown us that forming an acronym is a good strategy for remembering information. Each letter of an acronym triggers the recollection of long meanings or concepts. A clever acronym also entices interest. In searching for that clever acronym, we focus on two things: 1) Teaching success, and 2) Completeness of DES concepts delivered. Success is measured by the level of knowledge acquired by students at the end of the semester as well as how well they can apply such knowledge. We wanted instructors to have a tool that leads them to deliver a set of DES concepts that empower students in the use the DES methodology when looking for solutions to industry problems. In other words, we wanted both Teacher and Students to succeed; hence, the DES teaching framework has been defined using the acronym: SUCCESSFUL.

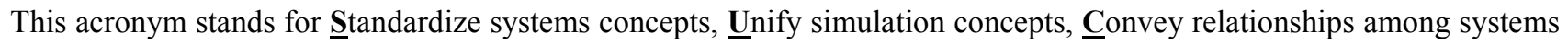

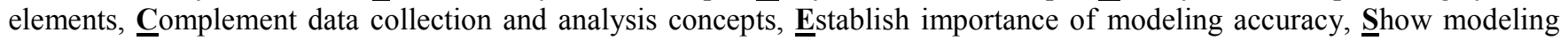

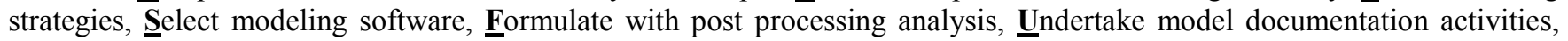

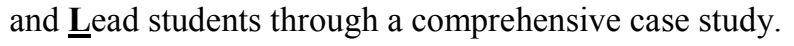

\section{THE FRAMEWORK}

The SUCCESSFUL framework is based on the requirements discussed in the last section. The 2-D matrix of the framework has 10 rows and 6 columns. Each row is dedicated to one element, which corresponds to each letter of the acronym. The columns describe actions to take, methods to use, tools for teaching, and tools for learning. The framework is shown in Table 2.

Table 2: The SUCCESSFUL Framework

\begin{tabular}{|c|c|c|c|c|c|}
\hline Label & \begin{tabular}{|c|} 
Element \\
\end{tabular} & Activity & Methods & Teaching Tools & Learning Tools \\
\hline $\mathbf{S}$ & $\begin{array}{l}\text { Standardize Systems Con- } \\
\text { cepts knowledge }\end{array}$ & & & & \\
\hline $\mathbf{U}$ & Unify simulation concepts & & & & \\
\hline $\mathbf{C}$ & $\begin{array}{l}\text { Convey relationships } \\
\text { among system elements }\end{array}$ & & & & \\
\hline $\mathbf{C}$ & $\begin{array}{l}\text { Complement data collec- } \\
\text { tion and analysis concepts } \\
\end{array}$ & & & & \\
\hline $\mathbf{E}$ & $\begin{array}{l}\text { Establish the importance of } \\
\text { modeling accuracy }\end{array}$ & & & & \\
\hline $\mathbf{S}$ & Show modeling strategies & & & & \\
\hline $\mathbf{S}$ & Select modeling software & & & & \\
\hline $\mathbf{F}$ & $\begin{array}{l}\text { Formulate with post } \\
\text { processing analysis }\end{array}$ & & & & \\
\hline $\mathbf{U}$ & $\begin{array}{l}\text { Undertake model docu- } \\
\text { mentation activities }\end{array}$ & & & & \\
\hline $\mathbf{L}$ & $\begin{array}{l}\text { Lead students through a } \\
\text { comprehensive case study }\end{array}$ & & & & \\
\hline
\end{tabular}

The actions that the instructor is expected to perform en each element (each letter) are given in Column named Activity. There is an inherent and implicit sense of time and sequence in this actions that maps the DES project cycle.

The framework guides instructors through an interlacing of concepts to build upon previous knowledge and to seed new knowledge in regards to systems analysis, DES, statistical analysis techniques and tools, modeling, and hands on activities.

The requirements of the framework have been satisfied as follows:

- Be easy to use: The structure of the framework is a familiar structure to all instructors. The rows in the framework have been arranged in such a way that concepts are delivered in a natural and coherent sequence; thus, the instructor does not have wrestle with what to teach first. The Methods and Tools columns of the framework have suggested methods and tools for each step. The instructor only needs select one.

- Have a checklist of key elements that must be in the DES course: The framework satisfies this requirement by providing a checklist of key concepts for each DES element. Thus, the second column is named Element. 


\section{Garcia and Centeno}

- Incorporate didactic strategies: The fourth column of the framework provides a set of methods to meet the element requirements. This column names as Method provides a list of recommended didactic strategies such as Case Method, PBL, or POL among other.

- Be easy to remember the elements of the framework: The acronym with which we have identified the framework is couple with the goal of every instructor when teaching a class: to be successful; thus, the acronym is easy to remember. Furthermore, the order of the letters in the acronym has made a map to a DES project, making the framework elements easy to remember.

\subsection{Framework Elements}

Standardize Systems Concepts knowledge: Even though a DES course is usually taken by students in the second half of their curricula, there is no guarantee they already understand what a system is. It is essential that students learn that a system is more than the sum of its individual elements. A typical mind set for students enrolling in a DES course is to solve problems using equations that give an exact solution, and using the equations of "that" section or chapter. Therefore, when they are confronted with an open ended, fuzzy problem typical of many real world systems, they try to take a short cut to find and answer simplifying a problem instead of dealing with the complexity of analyzing the system as a whole. In the latter, rest the foundations of the advantage of a DES model. Therefore, it is necessary for the instructor to start the course with standardization of the way the problems of a system may be analyzed. This may be achieve by remarking the systems concepts that the students possess or by introducing these concepts to them. Systems analysis offers to the students a way of understanding the problems and communicating this understanding to others. Once the students understand these concepts, they may start defining a simulation model for the system under study, considering whether a component of the problem situation should be included or not in the model. The student will also be able to define the components interactions and their relationship in term of a simulation jargon such as entities, resources, variables, attributes, and so on (Holmberg 2000).

Unify simulation concepts: In general, a simulation model is a mathematical formulation solved through a computer because cannot be solved by an analytical method; the model is a stochastic model where the variables in the model are evaluated at discrete periods of time (Kleijnen 2005). In a general sense, the students may have some experience with some kind of simulations before they take a DES course; for example, they may have used a continuous simulation software, such as a chemical process simulator; physical phenomena simulators; business games etc. So they have an idea of what simulation is; they may have taken an operations research course, where they lean techniques such as linear programming, which may have left them with the impression that simulation is an optimization tool. Either way, they usually do not have a clear grasp about the benefits and constraints of using DES. It is necessary to give them a unified set of concepts that seed fundamental knowledge about DES, the meaning of discrete events, and their benefits and limitations.

Convey relationships among system elements (detail level): When building a model, there is the temptation to include everything in it to make the model reliably par to the real world. However, the act of building a model of a system for improvement purposes is to isolate factors that affect the performance of the system. Therefore, the design of the model must be focused on the main objective of the improvement project. A lack of focus means more time and money invested in obtain a solution. Moreover, a higher level of detail in the simulation model does not imply higher accuracy, understandability and acceptability by the end-user. On the contrary, it may hide relevant relationships under a cloud of unnecessary details. Moving to the other end of the scale, on the other hand, may leave us with an over simplify model that cannot be used for analyzing the problem. The adequate level of details in a simulation model is that level which contains the minimum to achieve the improvement project goals (Kosturiak and Gregor 1998). This framework element may include several diagram modeling tools such as rich pictures, flow diagrams, sketches and so on, where the relationships among the system elements can be represented.

\subsection{Building the Simulation Model}

Complement data collection and analysis concepts: The availability of user-friendly software tools to collect data has increased the amount of data that a simulation analyst may reach. However, most of the time the data is not presented in the format required to be used in a simulation model, such that the time required by data gathering and validation is significant (Perera and Liyanage 2000). The old phrase of "garbage in, garbage out" applies to this framework element because if the analyst provides bad data, then the software will produce incorrect answers. Therefore, the instructor must include strategies to collect only the data required. Concepts about how to manage data, data mining methods, and data analysis may helps the students to reduce the time spent in obtaining the input data for a simulation model. The latter leads to a reduction in the cost of setting up the model inputs, particularly in the definition of probability distributions required for the simulation model. 


\section{Garcia and Centeno}

Establish the importance of modeling accuracy: Getting relevant and valid data does not guarantee a good simulation model. Building a model that does not represent the system under study will lead to bad conclusions. The modeling process should allow students to reduce the distance between the representation of the system and the real system. Meeting this requires ability to deal with the abstraction and knowledge about modeling methods (Bock and Yager 2001). Therefore, the instructor must deliver concepts that enable students to identify basic modeling difference between the use of a queue, storage, or conveyor in a simulation modeling; and understanding the difference between a scheduled down time and a failure.

Show modeling strategies: Modeling real systems requires developing skills to deal with complexity through abstraction and synthesis of a real system. If the DES course covers some specialized simulation software, most of the time students consider fun to play with the models and their animation. This leads them to focus more in the model animation details than in solving the problem they are analyzing (Paul et al. 2005). Hence, the DES course should contain assignments that lead the students to apply common modeling strategies such as considering a processes as a black box for modeling purposes, modeling problems with large stabilization time, model verification and validation strategies and so on.

Select modeling software: In the last two decades, many specialized simulation software have emerged. Each simulation software present advantages and disadvantages, particular modeling capabilities, challenges to be programmed, and different animation interfaces. In addition to these specialized packages, the instructor always has the option to use a spreadsheet package. The instructor must answer some relevant questions: How to lecture simulation modeling, either using spreadsheets or specialized simulation software? How much time to spend training the students in use of a particular simulation software? (Garcia and Garcia 2008). Selecting the appropriate software will depend on the course objectives, the availability of the software for the students, the previous courses taken by the students, and the knowledge of the instructor about a particular software.

\subsection{Postmortem Analysis}

Formulate with post-processing analysis: Although building a simulation model under the "as-is" conditions may be enough to analyze and improve a system, it is necessary to finish the students' training through an in-depth treatment of the postprocessing benefits that a DES model may offer. Some of these benefits are what if analysis, selection of the best scenario, design of experiments, statistical analysis, and so on. The challenge at this point is avoid spending too much time creating scenarios or making changes in the model, such that the time available to get a solution is over while the students continue generating tons of output data without sense. Poor planning in this post-analysis stage may lead no finding a solution or to get one without the required statistical support (Centeno and Carrillo 2001). Thus, the use of the model to go deeper in the analysis provides a robust problem solution, which is very important in real life applications.

\subsection{Final Documentation}

Undertake model documentation activities: Consultants or academicians, instead of the customer or final users, more commonly do Simulation applications. Most of the time simulation models do not receive maintenance or updates; thus, manager thinks twice in requesting other simulation model or require a model that the can maintenance or update as needed. The reuse of simulation models is not a new topic, actually is taking relevance in the simulation research community during the last years. The main drivers of this interest are reducing the analysis time required and economic reasons (Robinson et al. 2004). However, it is common found that a simulation model does not include the appropriate model and analysis documentation. A simulation model includeing a report describing how the model was built, the model assumption, simplifications, and data analysis performed will allow maintaining the model. Particularly, if someone else requires to do it after the project is delivered.

\subsection{An Integral DES Experience}

Lead students through a comprehensive case study: Once the students pass through all the basic concepts and relevant theory about DES, they are ready to learn hands on. The proposed framework suggests including a comprehensive final case, such that the students may learn by themselves. Here, didactic strategies such as PBL or CBL are useful to design a good case or problem, which covers all the previous topics taught during the course. In PBL, the learning is student-centered and takes place in small groups. PBL environments in higher education are intended to lead students to learn by themselves such that they will be capable of identifying the problems, analyze them and contributing to find possible solutions (Gijbels et al. 2005). 


\section{Garcia and Centeno}

\subsection{The S.U.C.C.E.S.S.F.U.L. Framework: An Example}

Providing a easy to remember and easy to use framework is a key issue to avoid rejection by the user. Table 3 shows how the SUCCESSFUL framework may be used in the organization of a DES course. A fourteen weeks course was considered in this example. Typically, the course is a 3-credit course, which implies that there are approximately 42 contact hours in the semester. About 3 of these hours are usually set aside for examinations. Even though the example is not exhaustive, may illustrate how the framework can be used in the design of a DES course.

\section{FUTURE WORK}

There are two possible paths to realize future work regarding this proposed framework. The first one related to improve the detail of each framework elements, for instance decomposing each framework elements in sub elements, thus the element of show modeling strategies may be decomposed in system simplification strategies (black box), modeling through analogue systems, or modeling without real data (modeling to design systems). The second possible path is to create a repository of applications of the framework such as the information shown in table 3. Thus, anyone interesting in getting ideas for a DES course will have an open place containing the experience of other instructors, which are lecturing a similar course. Besides these possible paths, this framework may be adapted or applied directly to other simulation application such as dynamic systems simulation. In addition, this framework may be tested over several semesters to be improved and refined.

\section{SUMMARY}

Teaching DES requires any help to facilitate the organization of the course due to the time available to cover all the concepts related with a simulation project. We have presented a framework easy to remember and use which is useful in reaching this organization. The framework proposed provides a PBL or POL environment. Simulation is a tool with a high potential to be used as a PBL or POL assignment, such that the students may learn by themselves relevant issues about a simulation project in the real life. The proposed framework intends to covers all the steps that are required to complete a simulation project. Moreover, provides a checklist of relevant topics that a DES course may include. This framework may be used by novel instructors or for those ones that have more experience lecturing to organize or improve the organization of their DES sections. 
Table 3: Organizing a DES course using the SUCCESSFUL Framework

\begin{tabular}{|c|c|c|c|c|c|}
\hline Label & Element & Activity & Methods & Teaching Tools & Student Tools \\
\hline $\mathbf{S}$ & $\begin{array}{l}\text { Standardize Systems } \\
\text { Concepts knowledge }\end{array}$ & $\begin{array}{l}\text { Define or take up again rele- } \\
\text { vant systems concepts such as } \\
\text { boundaries, elements, rela- } \\
\text { tionships, variables, attributes } \\
\text { of system. }\end{array}$ & $\begin{array}{l}\text { Problem based learning ex- } \\
\text { amples and homeworks }\end{array}$ & $\begin{array}{l}\text { Solved examples, Rich Pic- } \\
\text { tures, Event chain diagram, } \\
\text { relationship diagram and so } \\
\text { on. }\end{array}$ & $\begin{array}{l}\text { Course web page, solved ex- } \\
\text { amples, text book, course } \\
\text { handouts, instructor feedback }\end{array}$ \\
\hline $\mathbf{U}$ & $\begin{array}{l}\text { Unify simulation con- } \\
\text { cepts }\end{array}$ & $\begin{array}{l}\text { Define Simulation, talk about } \\
\text { limitations, advantages and } \\
\text { disadvantages, show some } \\
\text { real life applications. }\end{array}$ & $\begin{array}{l}\text { Literature Review, interview } \\
\text { an expert, interview a final } \\
\text { user. }\end{array}$ & $\begin{array}{l}\text { Conference proceedings, } \\
\text { open course videos (OCW). }\end{array}$ & $\begin{array}{l}\text { Simulation databases, inter- } \\
\text { views, web resources. }\end{array}$ \\
\hline $\mathbf{C}$ & $\begin{array}{l}\text { Convey relationships } \\
\text { among system elements }\end{array}$ & $\begin{array}{l}\text { Use basic modeling tools in } \\
\text { several detail levels such as } \\
\text { conceptual model, flow dia- } \\
\text { gram, event process diagrams. }\end{array}$ & $\begin{array}{l}\text { Show two detail levels of a } \\
\text { system. Comment about the } \\
\text { time required in both repre- } \\
\text { sentations. }\end{array}$ & $\begin{array}{l}\text { IDEF0 diagram, flow dia- } \\
\text { gram, event process dia- } \\
\text { grams, rich picture, model- } \\
\text { ing tools. }\end{array}$ & $\begin{array}{l}\text { Flow diagram, rich picture, } \\
\text { modeling tools }\end{array}$ \\
\hline $\mathbf{C}$ & $\begin{array}{l}\text { Complement data collec- } \\
\text { tion and analysis con- } \\
\text { cepts }\end{array}$ & $\begin{array}{l}\text { Analyze Data, Goodness of fit } \\
\text { analysis, talk about atypical } \\
\text { observations. }\end{array}$ & $\begin{array}{l}\text { PBL: Collect data from a } \\
\text { system. Identify atypical da- } \\
\text { ta, make a goodness of fit }\end{array}$ & $\begin{array}{l}\text { Software to perform statis- } \\
\text { tical analysis, an operation } \\
\text { record in video. }\end{array}$ & $\begin{array}{l}\text { Data collection sheets, statis- } \\
\text { tical analysis tools, probabili- } \\
\text { ty distribution references. }\end{array}$ \\
\hline $\mathbf{E}$ & $\begin{array}{l}\text { Establish the importance } \\
\text { of modeling accuracy }\end{array}$ & $\begin{array}{l}\text { Talk about model accuracy } \\
\text { and its implications on the } \\
\text { system analysis, provide ex- } \\
\text { amples. }\end{array}$ & $\begin{array}{l}\text { Case Method: comparison } \\
\text { among two problems with } \\
\text { different level of modeling } \\
\text { accuracy }\end{array}$ & $\begin{array}{l}\text { Open courseware on simula- } \\
\text { tion or modeling, simulation } \\
\text { expert interview }\end{array}$ & $\begin{array}{l}\text { Teamwork, web resources, } \\
\text { course handouts. }\end{array}$ \\
\hline $\mathbf{S}$ & $\begin{array}{l}\text { Show modeling strate- } \\
\text { gies }\end{array}$ & $\begin{array}{l}\text { Show examples of modeling } \\
\text { strategies of complex rela- } \\
\text { tionships and interactions. }\end{array}$ & $\begin{array}{l}\text { PBL: Solve problems } \\
\text { through several modeling } \\
\text { strategies }\end{array}$ & $\begin{array}{l}\text { PBL solution, papers regard- } \\
\text { ing modeling strategies }\end{array}$ & $\begin{array}{l}\text { Teamwork, course handouts, } \\
\text { web resources, open course- } \\
\text { ware. }\end{array}$ \\
\hline $\mathbf{S}$ & Select modeling software & $\begin{array}{l}\text { Explain the use of some mod- } \\
\text { eling software. }\end{array}$ & $\begin{array}{l}\text { PBL: Simulate a system us- } \\
\text { ing the strategies covered. }\end{array}$ & $\begin{array}{l}\text { Spreadsheets, specialized } \\
\text { simulation software }\end{array}$ & $\begin{array}{l}\text { Spreadsheet or software user } \\
\text { manual }\end{array}$ \\
\hline $\mathbf{F}$ & $\begin{array}{l}\text { Formulate with post } \\
\text { processing analysis }\end{array}$ & $\begin{array}{l}\text { Remark the benefits of realize } \\
\text { the postmortem analysis }\end{array}$ & $\begin{array}{l}\text { Case based Learning: Realize } \\
\text { the postmortem analysis to a } \\
\text { simulation model. }\end{array}$ & $\begin{array}{l}\text { What if analysis, design of } \\
\text { experiments, regression } \\
\text { analysis, validation tools. }\end{array}$ & $\begin{array}{l}\text { Statistical analysis software, } \\
\text { teamwork, scenarios analysis. }\end{array}$ \\
\hline $\mathbf{U}$ & $\begin{array}{l}\text { Undertake model docu- } \\
\text { mentation activities }\end{array}$ & $\begin{array}{l}\text { Show how to document mod- } \\
\text { els, remarks benefits. List in- } \\
\text { formation required for docu- } \\
\text { mentation purposes. }\end{array}$ & $\begin{array}{l}\text { Document a simulation mod- } \\
\text { el }\end{array}$ & $\begin{array}{l}\text { Template to document } \\
\text { projects, checklist of rele- } \\
\text { vant information }\end{array}$ & $\begin{array}{l}\text { Template to document } \\
\text { projects, checklist of relevant } \\
\text { information }\end{array}$ \\
\hline $\mathbf{L}$ & $\begin{array}{l}\text { Lead students through a } \\
\text { comprehensive case } \\
\text { study }\end{array}$ & $\begin{array}{l}\text { Provide a final PBL, POL or } \\
\text { CBL assignment, set up the } \\
\text { teams, clarify expected re- } \\
\text { sults, provide guide and feed- } \\
\text { back. }\end{array}$ & PBL, POL or CBL & $\begin{array}{l}\text { Simulation open course- } \\
\text { ware, PBL, POL and CBL } \\
\text { databases, Real projects do- } \\
\text { cumentation. }\end{array}$ & $\begin{array}{l}\text { Presentation tools, documen- } \\
\text { tation templates, simulation } \\
\text { software, statistical analysis } \\
\text { software. }\end{array}$ \\
\hline
\end{tabular}




\section{Garcia and Centeno}

\section{REFERENCES}

Bock, D. B., and S. E. Yager. 2001. Improving entity relationship modeling accuracy with novice data modelers. The Journal of Computer Information Systems 42(2): 69-75.

Centeno, M. A., M. Carrillo. 2001. Challenges of introducing simulation as decision making tool. In Proceedings of the 2001 Winter Simulation Conference, ed. B. A. Peters, J. S. Smith, D. J. Medeiros, and M. W. Rohrer, 17-21. Piscataway, New Jersey: Institute of Electrical and Electronics Engineers, Inc.

De Vin, L. J., and M. Jägstam. 2001. Why we need to offer a modeling and simulation engineering curriculum. In Proceedings of the 2001 Winter Simulation Conference, ed. B. A. Peters, J. S. Smith, D. J. Medeiros, and M. W. Rohrer, 766773. Piscataway, New Jersey: Institute of Electrical and Electronics Engineers, Inc.

Garcia, H., and E. Garcia. 2008. Enhancing simulation as improvement and decision support system tool. In Proceedings of the 2008 Winter Simulation Conference, ed. S. J. Mason, R. R. Hill, L. Mönch, O. Rose, T. Jefferson, and J. W. Fowler, 2549-2554. Piscataway, New Jersey: Institute of Electrical and Electronics Engineers, Inc.

Gijbels, D., F. Dochy, P. V. Bossche, and M. Segers. 2005. Effects of problem-based learning: A Meta-Analysis from the angle of assessment. Review of Educational Research. 75(2): 27-71.

Holmberg, S. 2000. A systems perspective on supply chain measurements. International Journal of Physical Distribution \& Logistic Management 30(10): 847-868.

ITESM 2009. Industrial and Systems Engineering curricula. http://www.itesm.edu/wps/portal?WCM_GLOBAL_ CONTEXT=/ITESMv2/Tecnol\%C3\%B3gico+de+Monterrey/Profesional/Programas $+\mathrm{de}+$ estudio/Carreras $+\overline{\text { profesionales }}$ / Ingenier\%C3\%ADa+y+Ciencias/IIS\#plan. [accessed June 12, 2009]

Jennings, D. 2002. Strategic Management: an evaluation of the use of three learning methods. Journal of Management Development 21(9/10): 655-665.

Kleijnen, J. P. C. 2005. Supply chain simulation tools and techniques: a survey. International Journal of Simulation \& Process Modelling 1(1/2): 82-89.

Kosanke, K., F. Vernadat, and M. Zelm. 1999. CIMOSA: enterprise engineering and integration. Computers in Industry 40(2/3): 83-97.

Kosturiak, J., and M. Gregor. 1998. FMS simulation: Some experience and recommendations. Simulation Practice and Theory 6(5): 423-442.

Lehaney, B., and R. J. Paul. 1996. Soft Systems Methodology and Simulation Modeling. In Proceedings of the 1996 Winter Simulation Conference, ed. J. M. Charnes, D. J. Morrice, D. T. Brunner, and J. J. Swain. 695-700. Piscataway, New Jersey: Institute of Electrical and Electronics Engineers, Inc.

Maxwell, N. L., J. R. Mergendoller, and Y. Bellisimo. 2004. Developing a problem-based learning simulation: An economics unit on trade. Simulation \& Gaming 35(4): 488-498.

Nikoukaran, J., V. Hlupic, R. J. Paul. 1999. Hierarchical framework for evaluating simulation software. Simulation Practice and Theory 7(3): 219-231.

Perera, T., and K. Liyanage. 2000. Methodology for rapid identification and collection of input data in the simulation of manufacturing systems. Simulation Practice and Theory 7(7): 645-656.

Paul, R. J., T. Eldabi, J. Kuljis, and S. J. E. Taylor. 2005. Is problem solving, or simulation model solving, mission critical?, In Proceedings of the 2005 Winter Simulation Conference, ed. M. E. Kuhl, N. M. Steiger, F. B. Armstrong, and J. A. Joines. 547-554. Piscataway, New Jersey: Institute of Electrical and Electronics Engineers, Inc.

Robinson, S., R. E. Nance, R. J. Paul, M. Pidd, and S. J. E. Taylor. 2004. Simulation model reuse: definitions, benefits and obstacles. Simulation Modelling Practice and Theory 12(7/8): 479-494.

Standridge, C. R., M. A. Centeno, B. Johansson, and I. Ståhl. 2005. Introducing simulation across the disciplines. In Proceedings of the 2005 Winter Simulation Conference, ed. M. E. Kuhl, N. M. Steiger, F. B. Armstrong, and J. A. Joines, 22742279. Piscataway, New Jersey: Institute of Electrical and Electronics Engineers, Inc.

Van der Zee, D. J., and J. G. A. J. Van der Vorst. 2005. A modeling framework for supply chain simulation: opportunities for improved decision making. Decision Sciences 36(1): 65-95.

Whitten, J. L., L. D. Bentley, and K. Dittman. 2004. Systems Analysis and Design Methods. $6^{\text {th }}$ ed. Boston: McGraw-Hill, Inc.

Wolfgang, K., and K. Østerbye. 1998. BetaSIM a framework for discrete event modeling and simulation. Simulation Practice and Theory 6(6): 573-599.

Zachman, J. A. 1999. A framework for information systems architecture. IBM Systems Journal 38(2/3): 454-470. 


\section{AUTHOR BIOGRAPHIES}

HERIBERTO GARCIA is an Associate Professor in the Industrial and Systems Engineering Department at the Tecnologico de Monterrey, Campus Monterrey. He received his BSME and MS on Industrial Engineering degrees from The Tecnologico de Monterrey (Monterrey, Mexico), he is PhD in Industrial and Systems Engineering from Florida International University. Professor Garcia is coauthor of the book "Simulacion y analisis de sistemas con ProModel" published in Spanish, he has published several conference papers and journals. His research and teaching interests include simulation, optimization, logistics, and supply chain management. He is a member of INFORMS, the Institute for Industrial Engineers, and the Council of Supply Chain Management Professionals. His email address is heriberto.garcia@itesm.mx.

MARTHA A. CENTENO is an Associate Professor in the Industrial and Systems Engineering Department at Florida International University. She has a B.S. in Chemical Engineering from ITESO University (Guadalajara, Mexico), a M. S. in Industrial Engineering from LSU (Baton Rouge, LA), and a PhD in Industrial Engineering from Texas A\&M University (College Station, Tx). Her current research interest are in Simulation Optimization, DOE and Simulation, SCM Modeling, and Emergency Response Modeling. She is a member of TВП, АПM, ASEE, IIE, INFORMS, and SCS. Her email address is centeno@fiu.edu. 